\title{
Escribir en la encrucijada: intertextualidad y polifonía en la obra de Chinua Achebe
}

\author{
Nair María ANAYA FERREIRA \\ Universidad Nacional Autónoma de México
}

\begin{abstract}
A sesenta años de la publicación de Things Fall Apart en 1958, la obra narrativa de Chinua Achebe continúa ofreciendo interesantes perspectivas de las condiciones históricas que dieron lugar a las sociedades africanas modernas. El objetivo de este artículo es analizar cómo a través de un uso magistral de la intertextualidad Achebe examina las relaciones interculturales surgidas del proceso expansionista europeo, así como la forma en que dichas relaciones configuraron las sociedades híbridas de la actualidad. Mi argumento plantea que, además de proponer una reflexión sobre la historia de Nigeria desde el periodo colonial (fines del siglo XIX) hasta los primeros años de independencia (décadas de 1960-1980), Achebe elabora un complejo metacomentario sobre los modos literarios de representación del África moderna.
\end{abstract}

PALABRAS ClAVE: Chinua Achebe, literatura africana, literatura poscolonial, intertextualidad.

Sixty years after the publication Things Fall Apart in 1958, Chinua Achebe's novels continue to offer interesting perspectives of the historic conditions that gave origin to modern African society. The aim of this article is to analyze the ways in which through a complex use of intertextuality, Achebe interrogates the intercultural relationships arising from European expansion, as well as the ways in which such relations shaped the hybrid societies of today. I contend that in his novels, Achebe not only examines Nigeria's history from the colonial era to the first years after independence, but also offers a complex metacommentary on the literary modes of representation of modern Africa.

KEYwORDS: Chinua Achebe, African literature, postcolonial literature, intertextuality.

El autor nigeriano Chinua Achebe (1930-2013) solía insistir en que siempre vivió en "a crossroads of cultures", una encrucijada desde la cual pudo atestiguar la profunda transformación social, cultural y política de África en el siglo Xx. Hijo de uno de los primeros conversos de la etnia igbo al anglicanismo, alrededor de 1904, Achebe creció inmerso en un contexto que lo sensibilizó a las ambivalentes repercusiones del fenómeno colonial y le permitió establecer una distancia crítica, a la vez que una postura conciliatoria, en relación con los cambios resultantes del proceso de transculturación ocurrido en el continente a raíz de la expansión europea. La postura afectiva e intelectual 
de Achebe está constituida, entonces, por dos particularidades que pueden parecer discrepantes pero que le permitieron, usadas de forma complementaria, aprehender, cuestionar y, en última instancia, reconfigurar tanto la historia de las tribus igbo y su incorporación a la nación moderna de Nigeria, como la metamorfosis identitaria que dicho proceso provocó. La primera tiene que ver con la idea de que vivir en la encrucijada le permitió tener una "doble visión" de su herencia cultural y política; la segunda proviene de la decisión de Achebe de ubicarse en el "middleground", no "un", sino el territorio intermedio en el que "the human spirit resists an abridgement of its humanity" (Achebe, 1993: 23). ${ }^{1}$

No es una exageración afirmar que la totalidad de la obra de este extraordinario escritor tiene como tema central un tópico recurrente en la literatura de todos los tiempos: la lucha del espíritu humano ante la adversidad. Realizar semejante aseveración puede parecer una trivialidad, pero insisto en ella pues puede ser un punto de partida provechoso para reflexionar acerca de la obra de Achebe, en particular, y de la literatura poscolonial, en general, desde una perspectiva que no se limite a considerar dicha producción literaria simplemente como una "traducción cultural", como una respuesta resentida contra la literatura europea, "derivada" de ésta o, peor aún, como un simple producto exótico de consumo para los lectores "occidentales". El propósito de este artículo es explorar cómo a través de un uso sutil de la intertextualidad Achebe examina las relaciones interculturales surgidas del proceso expansionista europeo, así como la forma en que dichas relaciones configuraron las sociedades híbridas que constituyen las naciones africanas de la actualidad. Mi argumento será que, además de proponer una reflexión sobre la historia de Nigeria desde el periodo colonial (fines del siglo XIX) hasta los primeros años de independencia (décadas de 1960-1980), Achebe elabora un complejo metacomentario sobre los modos literarios de representación en el África moderna. Un análisis de algunas estrategias discursivas en las novelas a partir de la intertextualidad permite identificar los puntos nodales en los que Achebe conjuga una variedad de cuestionamientos, entre los que se incluyen debatir la existencia de una verdad única acerca de la (no) historia de África; la (im)posibilidad de que sujetos africanos sean capaces no sólo de representarse a sí mismos, sino también de "significar”; la ¿equívoca? noción de la "universalidad” de la cultura propuesta por el liberalismo humanista "occidental". Así, es posible ver que Achebe establece un complejo dialogismo, en el sentido de "un choque entre lengua(je)s y enunciaciones que puede destacar no sólo una división social sino un espacio de formaciones discursivas radicalmente dividido dentro de un sujeto individual" (Allen, 2000: 165).

Sin duda alguna, Achebe tiene un lugar predominante en la literatura africana, al grado que es considerado como su figura fundacional. Para Simon Gikandi, uno de los mayores estudiosos de la literatura africana en inglés, Achebe "es el hombre que inventó la literatura africana porque fue capaz de mostrar, en la estructura y el uso de la lengua

\footnotetext{
1 “[E]1 espíritu humano resiste una restricción de su humanidad”. (Mi traducción.)
} 
[desde] su primera novela, que el futuro de la escritura africana no radicaba en la simple imitación de formas europeas, sino en la fusión de dichas formas con las tradiciones orales"(Gikandi, 2009: 303). La cita de Gikandi apunta al cambio en la percepción crítica y teórica que se fue gestando en el ámbito académico y editorial (en primera instancia en Europa, América del Norte y Australia, pero también en África misma) acerca de los autores africanos en lenguas europeas. Hasta principios de la década de los noventa, la tendencia era considerar la obra de estos autores simplemente en términos de producciones derivativas de la tradición europea, por lo que los ejemplos de intertextualidad no pasaban de ser tomados como muestras de la influencia de dicha tradición. Estas apreciaciones solían hacer caso omiso de las complejas estrategias discursivas empleadas por estos autores, mediante las cuales dieron cuenta de la ruptura epistémica que para las comunidades africanas significó la expoliación europea que desplazó su conocimiento, pero también del ejercicio de recuperación cultural e histórica que ha convertido a esta literatura en una de las más ricas y provocadoras de las últimas décadas. De hecho, una de las razones por las que estas expresiones literarias han sido objeto de tantos estudios críticos en las universidades de Europa y América del Norte es precisamente porque generan el tipo de aporías que resultan tan significativas en las teorías posestructuralistas predominantes en tiempos recientes.

La forma misma de la primera novela de Achebe, Things fall apart (1958), sugiere el estado de indecidibilidad que caracterizará a la literatura africana a partir de la década de los cincuenta, pues detrás de la apariencia de un registro lingüístico sencillo y de un realismo que parece dar un toque de "veracidad" antropológica a su narración, Achebe despliega estrategias que, de hecho, desestabilizan las convenciones asociadas con dichos modos discursivos. La primera parte de la novela vincula el ascenso y la caída del protagonista - el guerrero igbo Okonkwo - en Umuofia, aldea inscrita en una compleja red de relaciones jurídicas, religiosas, sociales y culturales que, de entrada, desestabiliza la noción decimonónica del primitivismo africano. La narración es de corte realista, con un inglés en apariencia simple o, como lo describiría Gilbert Phelps en The New Pelican Guide to English Literature, "un inglés impecablemente bueno" (Phelps, 1983: 330). Sin embargo, a pesar de que Okonkwo parece ser el personaje representativo de los valores igbo, la voz narrativa va estableciendo una distancia irónica que deja ver tanto los defectos del protagonista como las tensiones entre ciertas creencias y modos de organización de los igbo, las cuales contribuyen, en última instancia, al establecimiento paulatino de las instituciones británicas. La narración desempeña, entonces, varias funciones, que son a la vez complementarias y contradictorias. Por un lado, realiza una reconstrucción arqueológico-literaria de la vida de una aldea igbo justo antes de la llegada de los ingleses. Esta reconstrucción permite tener una idea clara de las tradiciones y la organización que rigen la vida de Umuofia, lo que da sentido, además, a la vida de sus habitantes. La voz narrativa desempeña aquí un papel fundamental, pues se desdobla para ser una especie de voz colectiva (encarnada en los narradores orales que parece contar las proezas del mismo Okonkwo), de voz antropológica que explica a los lectores ajenos las costumbres de la región e incluso 
de narrador heterodiegético cuya omnisciencia no logra dar cuenta, después de todo, de las paradojas del pensamiento igbo, pero sí vincula la dimensión mítica de Okonkwo, el protagonista, con la temporalidad cíclica de Umuofia en la primera parte de novela. El modo realista destaca, entonces, la verosimilitud de la recreación arqueológica, pero a la vez apunta hacia sus limitaciones: a pesar del carácter mimético de esta primera parte, los intentos de recrear el pasado precolonial de esa región resultan en una paradoja, en un proyecto imposible pues, como afirma Gikandi, el mundo igbo sólo es accesible al lector moderno en la medida en que ha sido representado por otros, sólo es accesible a Achebe mismo en la medida en que ha sido mediado por las fuentes del novelista, sean éstas igbo o coloniales, como, por ejemplo, las de G. T. Basden, misionero y antropólogo, autor de la famosa obra Among the Ibos in Nigeria (1912), quien, además, era amigo de los padres de Achebe y ofició su matrimonio (Gikandi, 1991: 31; Innes, 1990: 4; Mathuray, 2009: 39).

Por otro lado, más allá de estas paradojas, el realismo mimético de Things Fall Apart establece una relación intertextual de afirmación identitaria tanto con la novela colonial inglesa, como con ciertas abstracciones esencialistas eurocéntricas que excluían a África del mundo letrado. Achebe mencionó en repetidas ocasiones que en un principio su intención fue contrarrestar la imagen creada por autores como Joseph Conrad, Joyce Cary e incluso Graham Greene, o bien por los informes "científicos" de los funcionarios británicos, en los que el paisaje africano borraba la presencia y la historia de sus habitantes o, cuando éstos llegaban a aparecer, lo hacían ya como figuras desprovistas de su humanidad, ya como personajes exaltados, sin control de sus instintos y emociones. Basta recordar algunas de las descripciones de Marlow en la emblemática obra de Conrad, Heart of Darkness: "But suddenly, as we struggled round the bend, there would be a glimpse of rush walls, of peaked grass-roofs, a burst of yells, a whirl of black limbs, a mass of hands clapping, of feet stamping, of bodies swaying, of eyes rolling, under the droop of heavy and motionless foliage." O bien: "...I made out, deep in the tangled gloom, nakedbreasts, arms, legs, glaring eyes, — the bush was swarming with human limbs in movement, glistening, of bronze colour" (Conrad, 1981: 51, 64). ${ }^{2} \mathrm{El}$ hecho de que la tradición de la novela colonial, situada inevitablemente en las periferias del imperio, contribuyó a justificar la expansión imperial ha sido estudiado a fondo como parte del papel que la "textualidad" desempeñó para sustentar dicho fenómeno: "En un principio, las relaciones imperiales pueden haber sido establecidas por medio de las armas, la astucia y la enfermedad, pero se mantuvieron en su etapa interpelativa por medio de la textualidad, tanto institucional [...] como informalmente. El colonialismo (y su contraparte, el racismo) es una operación de discurso y, como tal, interpela a los

\footnotetext{
2 "De repente, mientras batallábamos alrededor de una curva, teníamos un vislumbre de muros de junco, de techos de paja en forma de pico, un estallido de alaridos, un remolino de extremidades negras, una masa de manos dando palmas, de pies pataleando, bajo el peso de un pesado e inmóvil foliaje".

"[...] distinguí en la enmarañada penumbra, pechos desnudos, brazos, piernas, ojos feroces; el monte pululaba con extremidades humanas en movimiento, resplandecientes, bronceados". (Mi traducción.)
} 
sujetos coloniales al incorporarlos en un sistema de representación en el que permanecen inscritos para siempre" (Tiffin y Lawson, 1994: 3).

Uno de los hipotextos de las tramas, las estrategias narrativas y los procesos para caracterizar a los personajes en las novelas de Achebe se encuentra, entonces, en ese tipo de discurso colonial. Las populares novelas situadas en África de Rider Haggard — como King Solomon's Mines (1885) o She (1887)_, de George Alfred Henty, quien publicó ciento veintidós novelas históricas de aventura entre 1867 y 1906 y cuyo protagonista suele ser un niño inglés que resuelve la trama en cualquier rincón del mundo, pasando por Heart of Darkness, hasta llegar a la obra de Joyce Cary - Aissa Saved (1931), The American Visitor (1932), The African Witch (1936) y Mister Johnson (1939) - y de Graham Greene (Heart of the Matter, 1948), por nombrar apenas algunos ejemplos, presentan, en diferentes grados, un retrato de África en el que la "otredad" del paisaje y sus habitantes perpetúa la oposición binaria civilización/barbarie. El crítico Abdul Jan Mohamed ha definido este proceso como "la economía de la alegoría maniquea", pues se fundamenta en "la transformación de la diferencia racial en una diferencia moral e inclusive metafísica” (JanMohamed, 1985: 1057). Así, ante la predominancia de un punto de vista único, Achebe desarrolla una multiplicidad de perspectivas; ante los estereotipos de africanos incoherentes, que responden al llamado de sus instintos y que carecen de una organización social coherente, presenta personajes complejos que comparten valores comunitarios, pero tienen una psicología individual; ante narradores que mantienen una distancia significativa con respecto a sus personajes y no promueven la identificación del lector con éstos, genera estrategias narrativas que convergen con los valores y los lenguajes (verbales y simbólicos) de la comunidad, pero que problematizan también las transformaciones ocasionadas por la invasión europea y discurren sobre los modos literarios en que dicha historia puede ser contada.

Quizá la estrategia discursiva más recurrente en la obra de Achebe (y en la de muchos autores de su generación) es la reconfiguración literaria de los diversos recursos culturales asociados con la oralidad de las sociedades originarias, de tal forma que dicha oralidad constituye un sustrato permanente que sustenta el palimpsesto híbrido de las manifestaciones modernas escritas en lenguas europeas (en este caso, por supuesto, el inglés). En el caso de Achebe, las referencias al intertexto de la oralidad cumplen varias funciones, que van del rescate arqueológico-literario de la cultura igbo precolonial hasta una compleja reflexión metaliteraria acerca del acto mismo de narrar, así como de la inestabilidad de los modos de significación poscoloniales. En un grado más extremo, la integración de formas orales en las diferentes novelas conlleva un cuestionamiento del grado en el que el fenómeno colonial tuvo repercusiones drásticas en las culturas locales, es decir, del grado en que la expansión europea provocó una ruptura epistémica de la que Achebe da cuenta, en primera instancia, en Things Fall Apart, y que constituye, por así decirlo, el hilo conductor general de su novelística.

La dimensión oral se manifiesta de diversas formas y constituye el medio para lograr la intención original de Achebe de doblegar la lengua colonial para obligarla a expresar la experiencia africana, nigeriana, igbo: "But it will have to be a new English, still in 
full communion with its ancestral home but altered to suit its new African surroundings" (Achebe, 1975: 65). Dicha dimensión discursiva aparece a nivel temático —alusiones a mitos, relatos, tradiciones y creencias-, pero sobre todo a nivel textual, como elemento intrínseco al desarrollo de la trama. No deja de ser irónico que la primera recepción de Achebe en Inglaterra señalara su sencillez y corrección lingüísticas, pues precisamente estos dos rasgos son los que desestabilizan el poder ideológico, político y cultural de la lengua inglesa en las novelas de este autor. En el caso de Things Fall Apart (cuya trama explora acontecimientos ocurridos por ahí de la década de 1890), el propósito de esta aparente sencillez es no sólo dar expresión a los ritmos de la oralidad igbo sino resaltar, narrativamente, que tanto la cultura igbo originaria como la tradición oral que la sustenta están en vías de extinción. Me explico: la textura sintáctica y estilística de la novela se logra mediante un predominio de la parataxis, el ritmo y la repetición, las cuales sirven, por un lado, para recrear los patrones estilísticos de los narradores orales tradicionales y, por otro, para ir introduciendo las cadencias cíclicas de la vida tribal que permiten tener una lectura más integral y congruente de la historia de África. Aunado a esto, la narración está completamente impregnada del entorno igbo: mediante el uso de símiles asentados en dicho entorno ("Okonkwo's fame had grown like a bush-fire in the harmattan" (Achebe, 1958: 3), ${ }^{3}$ de palabras en igbo y sonidos de tambores en momentos especiales, pero, sobre todo, mediante el énfasis en el papel de los proverbios, los relatos orales y el poder de la oratoria; Achebe visibiliza el predominio del valor de los códigos éticos y estéticos de su cultura, para romper así con la imagen monocromática de la literatura y la historiografía coloniales europeas.

La dimensión intertextual de la oralidad igbo tiene, entonces, dos funciones que se complementan entre sí pero que apuntan también a una serie de paradojas. En primer lugar, por el hecho mismo de incorporar la historia igbo en una narración escrita en inglés, Achebe articula el sincretismo resultante del proceso colonial que transformó la configuración grupal étnica del continente en el concepto europeo de "nación", una “creación arbitraria” establecida por los poderes europeos (Achebe, 1975: 58). En cierto sentido, este sincretismo adquiere la forma de una traducción cultural, pues lo que Achebe hace es "transponer" su cultura, la cual opera, en palabras de Maria Tymoczko, "como metatexto reescrito - explícita e implícitamente como trasfondo y primer plano- en el acto de creación literaria" (Tymoczko, 1999: 21). En segundo lugar, transformar la oralidad en una narración oral escrita permite, como afirma Abdul JanMohamed, "rescatar a las culturas orales de su transitoriedad"; lo que Achebe documenta es la "destrucción de una cultura oral por una cultura quirográfica" pero, paradójicamente, "al registrar la preocupación de dicha cultura oral con el presente", Achebe también "historiza su evanescencia” (JanMohamed, 1984 (2009): 585). Desde esta perspectiva, entonces, más que funcionar como traductor cultural, lo que Achebe logra es incorporar a la cultura oral (colonizada) en un palimpsesto en el que permanecen y subsisten los

\footnotetext{
3 "La fama de Okonkwo se había extendido como un incendio en el matorral durante el harmatán". (Mi traducción.)
} 
rastros de las sociedades originarias, para desestabilizar los intentos colonizadores de destruirlas y erradicarlas, de silenciarlas. La engañosa sencillez de su estilo narrativo sirve también, como apunta JanMohamed, para “desterritorializar” (1984 (2009): 587) la posición hegemónica del idioma inglés como vehículo para establecer jerarquías culturales y naturalizar valores alrededor de los conceptos de civilización (occidental) y primitivismo (periférico).

En el extremo opuesto de su palimpsesto intertextual, Achebe juega con el canon literario británico para establecer un contrapunto irónico acerca de las expectativas universalistas europeas, las cuales encuentran un sustento fundamental en la Biblia y en la narrativa cristiana que subyace el canon occidental. Además de los autores a los que me referí al principio del artículo, la obra de W. B. Yeats y T. S. Eliot genera una serie de vínculos multitemáticos con esa gran abstracción llamada "civilización occidental". Sólo las dos primeras novelas de Achebe tienen epígrafe: Things Fall Apart (1958) y No Longer at Ease (1960); sin embargo, la fuerza de los poemas parece abarcar el resto de su producción novelística - Arrow of God (1964), A Man of the People (1966) y Anthills of the Savannah (1987) — pues a través de ellos Achebe asienta un espacio ambiguo de interpretación que cuestiona y desplaza a la vez la noción europea de una historia lineal, progresiva y, en última instancia, excluyente, sustentada, sobre todo, en la tradición judeo-cristiana. De hecho, los títulos Things Fall Apart y No Longer at Ease provienen de poemas que tradicionalmente han sido considerados como paradigmáticos no sólo de la tradición literaria cristiana-europea-británica, sino también de un periodo en el que imperaba una insatisfacción moral y, casi podría decirse, espiritual, con las convenciones y los valores predominantes en el mundo europeo de las primeras décadas del siglo XX.

En sólo cuatro versos, el epígrafe tomado de "The Second Coming" proyecta la atmósfera apocalíptica y el tono ominoso que permea la novela: "Turning and turning in thewidening gyre / The falcon cannot hear the falconer; / Things fall apart; the centre cannot hold; / Mere anarchy is loosed upon the world". Sin embargo, Achebe desplaza la fuerza simbólica de la espiral yeatsiana ya sea como metáfora de la historia europea o bien como "patrón arquetípico que es reflejado una y otra vez por la vida toda, por todos los movimientos de la civilización” (Ellman, 1999: 231). Desde esta perspectiva, es posible afirmar, en concordancia con Roderick Wilson, que Achebe no es un "apocaliptista yeatsiano", pues no percibe la historia como un instrumento de la profecía, sino que, más bien, emplea a la historia como una herramienta de análisis que le permite legitimar un trasfondo cultural diferente (Wilson, 1978: 161). Achebe subvierte con ironía la visión abstracta y totalizadora que Yeats tenía de la historia (¿europea?) como un fenómeno cíclico y recurrente para inscribir en el vacío intersticial una nueva narración, en la que registra, en lugar de la extinción de la era cristiana, como afirma Lyn Innes, "el fin de la era no-cristiana en Nigeria Oriental” (Innes, 1990: 35).

No es gratuito que los epígrafes tengan en común los temas bíblicos de la revelación y la natividad, pues le permiten a Achebe establecer vínculos entre la tarea evangeli- 
zadora (siempre representada en términos de iluminación espiritual) de los misioneros cristianos en África y el profundo descontento moral y espiritual que imperaba en el mundo intelectual de la Inglaterra de principios del siglo Xx. "The Journey of the Magi" de T. S. Eliot — de donde proviene el epígrafe de la segunda novela No Longer at Ease - introduce, apropiadamente, el tema de la enajenación individual en un mundo que ha cambiado a tal grado que uno se siente extranjero y cuya constante transformación ha provocado que los valores religiosos (cristianos, por supuesto) hayan dejado de cumplir con su objetivo espiritual: "We returned to our places, these Kingdoms, / But no longer at ease here, in the old dispensation, / With an alien people clutching their gods. / I should be glad of another death". La intertextualidad funciona aquí en varias direcciones. En primer lugar, en relación con el protagonista - Obi, nieto de Okonkwo, el héroe trágico de Things Fall Apart, e hijo de Nwoye, quien al convertirse al cristianismo adquirió el nombre de Isaac-, contribuye a articular la sensación de vacío y desesperanza que lo caracterizan. Su utópica ambición de formar parte de la administración colonial en una Nigeria autónoma pero aún no independiente, luego de pasar varios años estudiando en Inglaterra (es decir, preparándose para contribuir al "nacimiento" de una nueva nación) resulta ser un fracaso mayor, pues nunca logra reconciliar la yuxtaposición de las dos culturas que ahora configuran la identidad nacional. Peor todavía, el hecho de estar conformado ideológica y emocionalmente por la tradición literaria inglesa obstruye toda posibilidad de alcanzar una comprensión profunda de la nueva realidad de su país, lo cual ocasiona, en última instancia, su caída.

En este sentido, se podría afirmar que su conformación intelectual inglesa ocasiona que pierda su capacidad de comprender los valores éticos igbo que aún sustentan ese nuevo constructo llamado Nigeria; es decir, su configuración mental literaria lo aleja de la tradición oral igbo y, por tanto, de los valores que daban sentido a las relaciones sociales de su comunidad, proceso que queda representado en la gradual desaparición de los proverbios como elemento de cohesión cultural. En la caracterización de Obi, Achebe explora magistralmente los mecanismos de enajenación colonial que, a través de la imposición de la lengua y la cultura imperial, transformaron radicalmente el universo mental de los pueblos colonizados. Obi ejemplifica cómo las tensiones y contradicciones tan estudiadas por Frantz Fanon llevan a un rompimiento del individuo consigo mismo y con la sociedad que lo rodea. A pesar de sus buenas intenciones y de un empeño genuino por contribuir al bienestar de su familia y su nación, Obi no logra percibir su realidad más que con los ojos textuales de Joseph Conrad, Graham Greene, T. S. Eliot, W. H. Auden o A. E. Housman. De este último asume sus valores estéticos, los cuales, paradójicamente, lo llevan a escribir poemas patrióticos, dedicados a Nigeria, en tonos románticos e inscritos en el modo pastoral, nostálgico, de la tradición georgiana inglesa. Es decir, Obi ha perdido completamente el vínculo intelectual y emocional con la tradición oral (y, por tanto, con su cultura) que continúa prevaleciendo en la sociedad colonizada y que sobrevive incluso en medio del proceso de urbanización que transformó la geografía y la forma de vida de la región. Su falta de capacidad para entender (o al menos disfrutar melódica y rítmicamente) las canciones de los 
trabajadores en el camión que lo lleva a su pueblo natal no es más que un reflejo de la confusión mental que lo aqueja, la cual provoca indiferencia, un alejamiento total de su familia y de la comunidad, y, peor aún, una incapacidad de compromiso ético ante el aborto, obligado por las circunstancias, de su novia.

El periodo de transición entre la llegada de los misioneros de Things Fall Apart y la Nigeria autónoma de la década de los sesenta de No Longer at Ease es el tema de la tercera novela de Achebe, Arrow of God, publicada en 1964. En ella, Achebeexplora el proceso de modernización que transformó el paisaje local, pero sobre todo analiza las tensiones surgidas de la superposición de estructuras políticas y sociales. Basada en un incidente real ocurrido en 1910, el argumento trata acerca de la problemática construcción de una carretera y de las consecuencias de la captura y prisión del sacerdote Ezeulu por negarse a aceptar el nombramiento de warrant chief — cargo vital para la política de administración indirecta planeada por Lord Frederick Douglas - lo cual ocasiona que no pueda anunciar la aparición de la luna llena para llevar a cabo el festival del nuevo ñame. Considerada por Achebe como su novela más lograda, Arrow of God contrapone una textura narrativa en la que parodia el discurso colonial tanto de los documentos oficiales británicos como de las novelas de Joyce Cary con un conflicto religioso de fondo, el cual problematiza la metáfora de la revelación divina que subyace los epígrafes de Yeats y Eliot. A partir de una variedad de perspectivas y focalizaciones narrativas - que traen a un primer plano tanto a los funcionarios ingleses como a personajes igbos que representan diferentes posturas ante la colonizaciónAchebe examina el poder de la(s) lengua(s) para generar conocimiento, aprehender el mundo y producir significado. En última instancia, cuestiona la posibilidad de que exista una verdad única que, en el contexto colonial, se asociaba con el alfabetismo y, a partir de éste, con el poder unívoco de la Biblia.

En este sentido, Arrow of God juega con la intertextualidad para controvertir las drásticas y paradójicas repercusiones del proceso alfabetizador (y por tanto, de la educación) colonial en los sistemas de conocimiento de las comunidades locales. En "The coming of literacy: Arrow of God by Chinua Achebe", Neil Ten Kortenaar analiza, de forma sutil pero contundente, el devastador efecto de la educación colonial y la lectura en las relaciones familiares y tribales, ejemplificado en la aparentemente inocente escena en la que Oduche - hijo de Ezeulu el sacerdote - lee un libro de texto en la choza, apropiándose de la única vela disponible. Su aislamiento, pero sobre todo su capacidad de recitar palabras que para su familia resultan misteriosas, deja de manifiesto, como afirma Ten Kortenaar, "su acceso privilegiado a fuentes privadas de conocimiento y autoridad" (Ten Kortenaar, 2011: 24). Aprender a leer, entonces, no sólo rompe con la vida comunitaria, en especial con los momentos íntimos de los relatos orales narrados por la madre, sino que también "resulta inseparable de la presencia de los misioneros cristianos que establecieron la ortografía igbo, publicaron el libro de texto que [Oduche] lee, y construyeron la escuela a la que asiste" (Ten Kortenaar, 2011: 25). No sorprende entonces que para Oduche — como para Enoch en Things - el pitón sagrado pierda su valor religioso en la escena que origina el despliegue de acontecimientos que llevarán a la locura de su padre, Ezeulu. 
No es una exageración afirmar que Arrow of God es, por así decirlo, una novela que explora el proceso alfabetizador en África y la conflictiva interacción entre el mundo de la oralidad y el de la literacidad, interacción que no sólo transformó la epistemología local, sino que modificó incluso los valores éticos y morales de las comunidades. Sin embargo, como sugiere Ten Kortenaar, la novela no pretende descartar el alfabetismo y la escritura como elementos disruptivos, sino problematizar su relación con la oralidad. Más aún, Arrow "desea evadir lo que presenta como el poder de la literacidad para reducir y fijar el mundo, pero también desea controlar la circulación de este poder para crear comunidad. Parte de la estrategia narrativa consiste en trastocar los binarios que equipararían la literacidad con lo británico y la oralidad con lo igbo" (Ten Kortenaar, 2011: 56). Escribiendo en la encrucijada, la contribución central de Achebe es precisamente romper con las reductivas oposiciones binarias de la epistemología colonialista eurocéntrica mediante la problematización, por un lado, de las implicaciones del proceso de desplazamiento físico y material de las culturas nativas, pero por otro, y sobre todo, de las falacias que pueden surgir de simplificar el poder del alfabetismo y la escritura por encima de la tradición oral (y de asociar esto con una noción de superioridad cultural intrínseca vinculada con el desarrollo y la modernidad).

Así, lo que Achebe ofrece es una representación compleja de las condiciones históricas que dieron lugar a las sociedades africanas modernas, en las cuales la conciencia identitaria pasó de ser tribal y étnica a nacional. Las tensiones textuales representadas en la difícil relación entre oralidad y escritura y, en otro sentido, entre la función social y comunitaria de los proverbios y una visión más individualista asociada con la lectoescritura en el sentido europeo, articulan, entonces, cómo las cuestiones relacionadas con la lengua, el poder, la autoridad y el conocimiento fueron elementos subyacentes del periodo transicional del colonialismo a las primeras décadas de la independencia de Nigeria. En las dos últimas novelas, A Man of thePeople y Anthills of the Savannah, estas problemáticas giran alrededor del frágil establecimiento de un modelo democrático republicano en sociedades marcadas por la inequidad y la marginación (tanto económica y política como educativa, cultural y lingüística). Una explicación posible para las dramáticas realidades de las naciones africanas contemporáneas (que podría ampliarse al resto del Tercer Mundo) radica precisamente en el rompimiento de las élites ilustradas y las clases gobernantes con las tradiciones locales o bien, como sugiere Achebe, en su incapacidad para participar en y de (en el sentido de tomar parte y compartir) las nuevas formas lingüísticas híbridas que dejan de manifiesto el inexorable e irreversible sincretismo surgido de la colonización.

En A Man of the People, Achebe caracteriza irónicamente a los políticos-caciques que a lo largo y ancho del mundo han aprovechado su posición para obtener ganancias personales pero, además, al situar la trama en los primeros años de la década de los sesenta, explora, por un lado, las conflictivas tensiones entre el campo y la ciudadcapital experimentadas y compartidas por los llamados países en desarrollo y, por otro, la vulnerabilidad de los primeros años de una nación recién independizada, cuyo gobierno fue incapaz de articular la multiplicidad de fuerzas étnicas y políticas (y por 
tanto, lingüísticas y culturales). Como en toda su producción literaria, Achebe explora las repercusiones de los fenómenos históricos a través de estrategias narrativas que constituyen, en sí mismas, metacomentarios sobre la posibilidad (o imposibilidad) de la lengua para enunciar y articular la realidad inmediata. Como afirma Gikandi, "[u]no de los temas más persistentes en $A$ Man of the People es la dificultad del narrador para articular una narración maestra que pueda ser empleada con el fin de explicar los acontecimientos históricos y sus repercusiones para los individuos y las sociedades" (Gikandi, 1991: 106). No es gratuito, entonces, que Achebe adopte una narración homodiegética "para dramatizar los problemas que encontramos en el momento en que intentamos entender un mundo que necesita todavía establecer sus fundamentos, un mundo en el que las relaciones temporales se han derrumbado y la causalidad evade a los intérpretes, especialmente cuando éstos son actores del drama de la nación" (Gikandi, 1991: 106).

Así, el retórico recuento de los acontecimientos que llevarán a un golpe de estado por parte del narrador Odili no hace más que socavar su intención de proveer de significado a una serie de acciones y conductas (en especial del Jefe Nanga, el político corrupto que protagoniza el nivel político de la trama) que, en el contexto, carecen de coherencia e incluso significación. Una vez más, el hecho de que Odili haya sido educado eurocéntricamente y represente a los maestros encargados de transmitir una ideología marcada, aún, por los valores coloniales, obstruye su percepción del entorno cultural y de los sucesos políticos que subyacen la trama. Como miembro de la élite nacionalista, está caracterizado paradójicamente, pues a la vez que desprecia las tradiciones locales (a las que considera como simple folclor), percibe la duplicidad del lenguaje de los políticos y el creciente deterioro político de la recién fundada nación. La trama explorará, entonces, su toma de conciencia de la necesidad (no resuelta) de abandonar su configuración intelectual europeizada (la cual, como narrador, lo vuelve cínico e insensible) para tratar de comprender el poder de la tradición oral representada, de nuevo, por los proverbios y los mitos de creación, en especial los femeninos - y de la hibridez lingüística como manifestación sincrética del cambio cultural. La novela muestra con lucidez cómo los diversos modos y registros lingüísticos están configurados por dimensiones textuales y culturales que adquieren significados distintos según la pertenencia o afiliación a uno u otro grupo étnico o social pero que, en última instancia, como sugiere Gikandi, no permite que los personajes encuentren un idiom o modo lingüístico compartido a nivel nacional (Gikandi, 1991: 121).

Las estrategias narrativas empleadas por Achebe en su obra novelística responden, sin lugar a dudas, a su preocupación por explorar la violenta transformación histórica del continente (Nigeria, en particular) a partir de un cuestionamiento de las prácticas lingüísticas y modos de representación tanto de las sociedades originarias como de las europeas. En este sentido, se puede decir que cada novela asume una postura narrativa diferente, que va de una voz colectiva representativa de la tradición oral comunitaria a narradores menos confiables e incluso más cínicos cuya cosmovisión fracturada por su afiliación británica obstruye su capacidad de entender la oralidad y, por tanto, la 


\section{$178 \square$ ESCRIBIR EN LA ENCRUCIJADA: INTERTEXTUALIDAD Y POLIFONÍA}

fuerza de la cultura popular que constituye, para Achebe, así como para muchos de los autores de la región, el fundamento de la identidad africana. En la medida en que la trama de cada novela se enfoca en periodos históricos diferentes, Achebe reflexiona también sobre cuál es el modo narrativo adecuado para la representación correspondiente y, sobre todo, reflexiona sobre la función que cada narrador o storyteller tiene frente a su material creativo. En A Man of the People la incapacidad que muestra el narrador para percibir la gravedad de los acontecimientos de su entorno - y que concluirán con un golpe de estado - va en relación directa con su incapacidad de comprender la voz del pueblo, expresada en proverbios ya matizados por la presencia del pidgin, la lengua híbrida por excelencia. La ironía implícita borda en lo satírico (a partir precisamente del cuestionamiento de lo que significa pertenecer o ser de la gente, "of the people") pero no deja de apuntar a la realidad extradiegética que vivía Nigeria apenas seis años después de su independencia. Dando muestra de una percepción política casi profética, Achebe anticipó narrativamente el golpe de estado que sacudió a Nigeria apenas meses después de la publicación de la novela. El que se le acusara, incluso, de haber estado detrás de este evento, así como los dramáticos acontecimientos que desembocaron en la guerra civil en la que Biafra buscaba la secesión, desviaron los esfuerzos creativos del autor, quien fungió como portavoz internacional de Biafra.

Anthills of the Savannah fue publicada veintiún años después (en 1987) y se ocupa de una trama estructuralmente más compleja que las novelas anteriores, pues la multiplicidad de perspectivas narrativas y su abordaje de la situación política en Nigeria rebasa con mucho la preocupación previa por centrarse en un análisis retrospectivo del colonialismo. La novela explora las repercusiones de la rápida descomposición social y política en la que cayó Nigeria en menos de treinta años de independencia y analiza esta situación en el contexto global más amplio de violencia y desilusión política que prevaleció en el mundo en los años ochenta. (No por nada la única referencia a América Latina alude a las formas de tortura que el dictador aprendió de sus congéneres latinoamericanos.) Sin embargo, el objetivo central radica más bien en examinar las formas en que dichas realidades pueden ser descritas o relatadas, así como la responsabilidad ética y moral que asume quien decide articular dichas narraciones. Así, con Anthills of the Savannah, Achebe concluye la búsqueda iniciada en Things Fall Apart por encontrar los modos y recursos narrativos que permitieran lograr una representación de África desde África misma. No es gratuito, entonces, que el entramado narrativo esté configurado por una densidad intertextual sumamente compleja mediante la cual Achebe conversa no sólo con la tradición oral africana y la europea canónica, sino que introduce ahora un debate con la tradición escritural-literaria establecida en diferentes países por autores como Leopold Sedar Senghor, David Diop, Ngũgĩ wa Thiong'o, Wole Soyinka, Nurruddin Farah y Christopher Okigbo, joven poeta que murió en la guerra y a quien Achebe alude en diferentes obras, pero en especial en esta novela, en la que Okigbo es la base para la caracterización de uno de los protagonistas, Ikem Osodi, también asesinado en la trama. 
En lo que puede ser considerado un ejemplo del proceso de autoaprehensión —que para Wole Soyinka es el elemento fundamental de la conciencia descolonizadora, es decir, cómo comprender y aprehender el mundo africano y la realidad africana en toda su complejidad desde África misma y no a partir de modelos europeos (Soyinka, 1976, viii-xi) - Achebe hace hincapié en el valor del narrador oral como piedra de toque para examinar no sólo la importancia de las narraciones en las configuraciones nacionales, sino también como bisagra para interrogar otros aspectos extradiegéticos como el entorno ideológico y político que produce cierto tipo de enunciaciones discursivas, o bien la posibilidad de que la élite intelectual logre una identificación genuina y desde la raíz con el resto de la población, en especial los grupos marginados y pobres. En este sentido, cabe destacar la transformación personal, ideológica e incluso ética de Beatrice Okoh, Ikem Osodi y Chris Oriko, los tres protagonistas alrededor de quienes está focalizada la historia, narradores en ciertos momentos, educados en Inglaterra e inmiscuidos involuntariamente en la enredada trama política del país, la república ficcional de Kangan, que representa no sólo a Nigeria sino al resto de las repúblicas africanas cuyo proceso de transición poscolonial no puede escapar de la intervención político-militar de los países europeos y Estados Unidos. En los tres casos, un acercamiento circunstancial a diversos grupos de las clases populares los lleva a pensar un futuro posible, utópico, de la nación, a través del reconocimiento de la tradición oral, ya hibridizada, como medio unificador. Para Ikem, el reconocimiento acontece en un momento crucial de la trama, cuando participa en una reunión de la comunidad de Abazon — que reclama acceso al agua en su territorio-y comprende, después de escuchar a uno de los ancianos de grupo, la importancia de la oralidad y, sobre todo, de la creación de historias. Las palabras del anciano pueden ser interpretadas como un metacomentario por parte de Achebe acerca de su función como novelista, pero también acerca de la función de la literatura para comprender las paradojas del momento poscolonial:

The sounding of the battle-drum is important; the fierce waging of the war itself is important; and the telling of the story afterwards - each is important in its own way. I tell you there is not one of them we could do without...

So why do I say that the story is chief among his fellows? [...] Because it is only the story can continue beyond the war and the warrior. It is the story that oulives the sound of war-drums and the exploits of brave fighters. It is the story, not the others, that saves our progeny from blundering like blind beggars into the spikes of the cactus fence. The story is our escort; without it, we are blind. Does the blind man own his escort? No, neither do we the story; rather it is the story that owns and directs us. It is the thing that makes us different from cattle; it is the mark on the face that sets one people apart from their neighbours (Achebe, 1987: 123-124). ${ }^{4}$

\footnotetext{
${ }^{4}$ El sonido del tambor en la batalla es importante. La feroz declaración de guerra es importante, así como contar la historia después; cada uno, a su manera, es importante. Les digo que no podemos prescindir de ninguno de ellos...
} 
O como insiste Gikandi, "el relato, al reescribir la historia y crear una versión atemporal y autónoma de los acontecimientos de tal forma que éstos puedan hablar a las generaciones futuras, rebate el intento constante, por parte de las instituciones poderosas, de reprimir aquellas memorias colectivas que amenazan el control, memorias que son borradas cuando se textualiza la historia oficial”. Más aún, en un mundo que está de cabeza, y en la medida en que Achebe cree que la realidad se ha convertido en un objeto prohibido, el acto narrativo "debe estar orientado hacia la institución de una hermenéutica africana que pueda contribuir a recuperar los objetos escondidos de la historia contemporánea [de África]" (Gikandi, 1991: 131).

En la caracterización de Beatrice, Achebe concentra una serie de problemáticas que le permiten articular su preocupación no sólo por recuperar narrativamente dichos objetos escondidos de la historia contemporánea de Nigeria, sino también por ofrecer vislumbres de vías alternas para una posible transición social fundamentada en la participación de la mujer y de las clases populares, representadas, ambas, en la expresión lingüística del pidgin. A lo largo de la trama, Beatrice — cuyo nombre alude, sin duda, a Dante - pasa de vivir en una situación de privilegio elitista a una toma radical de conciencia tanto de la inequitativa realidad social de su país, como de los modos discursivos que han representado dicha realidad y la historia que ha llevado a ella. En el proceso, Beatrice tiene varias epifanías en las que reconoce el grado en que su educación colonizada ha configurado su mentalidad - empezando, por supuesto, por el nombre europeo que emplea por sobre su nombre igbo, Nwanyibuife, "una mujer también es algo", con el que su padre manifestaba su inconformidad por haber engendrado sólo mujeres-, pero también la importancia de los diversos elementos orales que la han acompañado a lo largo de su vida. Reconocer que la tradición oral permanecía latente en su familia a pesar de las prohibiciones de su padre — cuya conversión al cristianismo acentuó su fanatismo y violencia - contribuye a su posterior identificación del mito femenino de Idemili, el cual entreteje un complejo hilo narrativo que problematiza varias de las temáticas exploradas en la novela.

Comenzando por el rasgo distintivo de Idemili, expresado en el epíteto de "Pilar de agua", Achebe ofrece un contrapunto discursivo al tema de la sequía y la falta de agua como medio de control político que constituye uno de los hilos conductores de la trama. $\mathrm{Al}$ asociar el mito con Beatrice, construye un complejo entramado por medio del cual reflexiona sobre el carácter moral de la autoridad y, a partir de ahí, abre un espacio para vislumbrar posibilidades de cambio social fundamentadas en una mayor participación de la mujer. No es gratuito, entonces, que la creciente sensibilidad de Beatrice hacia

Así que, ¿por qué digo que la historia es líder entre sus camaradas? [...] Porque es sólo la historia la que puede avanzar más allá de la guerra y el guerrero. Es la historia la que sobrevive el sonido de los tambores de guerra y las hazañas de los valientes luchadores. Es la historia, no lo demás, lo que salva a nuestra progenie de dar tumbos como los mendigos ciegos con las espinas de las cercas de cactus. La historia es nuestra escolta; sin ella, estamos ciegos. ¿Acaso el ciego es dueño de su guía? No, como tampoco nosotros somos dueños de la historia; más bien la historia nos posee y nos guía. Es lo que nos hace diferentes del ganado; es la marca en el rostro que distingue a un pueblo de sus vecinos. (Mi traducción.) 
los modos orales que la rodean vaya acompañada también de un cuestionamiento de la forma en que algunos proverbios y expresiones idiomáticas articulan el control patriarcal que debe ser modificado. Ante frases como "A totally reasonable wife is always pregnant" (Achebe, 1987: 88) ${ }^{5}$, el mito de Idemili alerta a Beatrice sobre el poder del lenguaje para configurar la realidad, de tal modo que, al final de la novela y como única sobreviviente, después de que Iken y Chris son asesinados, ella asume el liderazgo de un grupo en el que confluyen personas de diferentes religiones, etnias y estratos sociales. Estratégicamente, y a pesar del panorama tan devastador, Achebe concluye con una perspectiva esperanzadora, que lleva una fuerte carga simbólica: el bautizo que Beatrice organiza para dar nombre a la hija recién nacida de su sirvienta Elewa (que era la novia de Ikem) se convierte en una ceremonia que reconstruye los rituales igbo y se vuelve a dar valor a las palabras que han sido desacralizadas por la guerra y la corrupción. Beatrice asume su responsabilidad como mujer y como nigeriana educada que parece romper con la tradición pero que, de hecho, simbólicamente, la refuerza. Decide bautizar a la niña con un nombre masculino - Amaechina, que el camino nunca se cierre - con la esperanza de que sea la pequeña quien herede los valores y la lucha de Ikem, su padre. En este contexto destaca que las últimas palabras de la novela no queden en boca de Beatrice sino de Elewa, y que éstas sean enunciadas en pidgin, la lengua de una cultura híbrida que busca aceptar su nueva realidad poscolonial.

\section{Obras consultadas}

ACHEBE, Chinua. 1993. "The Education of a British-Protected Child”. The Education of a British-Protected Child. Essays. Nueva York: Alfred A. Knopf, 2009. 1987. Anthills of the Savannah. Londres: Picador / Heinemann.

1975. "The African Writer and the English Language". Chinua Achebe's Things Fall Apart. Ed. Isidore OKPEWHO. Oxford: Oxford University Press, 2003. (Casebook Series)

1958. Things Fall Apart. Londres: Heinemann.

AlLEN, Graham. 2000. Intertextuality. Londres: Routledge. (The New Critical Idiom)

ConRaD, Joseph. 1981. Heart of Darkness (1902). Harmondsworth: Penguin.

Ellman, Richard. 1999. Yeats. The Man and the Masks (1948). Nueva York / Londres: W. W. Norton \& Co.

GIKANDI, Simon. 2009. "Chinua Achebe and the Invention of African Literature". The Norton Critical Edition of Things Fall Apart by Chinua Achebe. Ed. Francis Abiola IRELE. Nueva York / Londres: Norton.

\footnotetext{
5 “Una esposa totalmente razonable siempre está embarazada". (Mi traducción.)
} 
1991. Reading Chinua Achebe. Language and Ideology in Fiction. Londres / Portsmouth, James Currey / Heinemann. (Studies in African Literature Series)

InNeS, C. L. 1990. Chinua Achebe. Cambridge: Cambridge University Press.

JanMohamed, Abdul. 1985. "The Economy of Manichean Allegory. The Function of Racial Difference in Colonialist Literature". Diana BRYDON, ed., Postcolonialism. Critical Concepts in Literary and Cultural Studies. Londres: Routledge, 2000. Vol III. Pp. 1055-1084.

1984. "Sophisticated Primitivism: The Syncretism of Oral and Literate Modes in Achebe's Things Fall Apart". Chinua AcheBe, Things Fall Apart. Ed. Francis Abiola IRELE. Nueva York: Norton, 2009. (A Norton Critical Edition)

MathURAY, Mark. 2009. On the Sacred in African Literature. Old Gods and New Worlds. Houndmills, Hampshire: Palgrave Macmillan.

PhelPS, Gilbert. 1983. "Two Nigerian Writers: Chinua Achebe and Wole Soyinka". Boris Ford, ed., The New Pelican Guide to English Literature. Londres: Penguin. Vol. 8. (The Present)

SoYINKA, Wole. 1976. Myth, Literature and the African World. Cambridge: Cambridge University Press.

Ten KortenaAR, Neil. 2011. "The coming of literacy: Arrow of God by Chinua Achebe". Postcolonial Literature and the Impact of Literacy. Cambridge: Cambridge University Press.

Tiffin, Chris y Alan Lawson. 1994. "Introduction. Thetextuality of Empire”. Chris Tiffin y Alan LaWson, eds. De-Scribing Empire. Post-colonialism and textuality. Londres: Routledge.

TYмoсzKo, Maria. 1999. "Post-colonial writing and literary translation". Susan Bassnett y Harish Trivedi, eds., Post-colonial Translation. Theory and Practice. Londres: Routledge.

WILSON, Roderick. 1978. "Eliot and Achebe: An Analysis of some Formal and Philosophical Qualities of 'No Longer at Ease"'. C. L. INNES y Bernth LindFORS, eds., Critical Perspectives on Chinua Achebe. Londres: Heinemann. 